\title{
International Learning on Increasing the Value and Effectiveness of Primary Care (I LIVE PC) New Zealand
}

\author{
Felicity Goodyear-Smith, MBChB, MGP, Robin Gauld, MA, PhD, \\ Jacqueline Cumming, BA, MA, Dip Health Econ, PhD, Bev O'Keefe, MBChB, \\ Harry Pert, MBChB, and Paul McCormack, MBChB
}

New Zealand (NZ) has a central government-driven, tax-funded health system with the state as dominant payer. The NZ experience precedes and endorses the US concept of patient-centered medical homes providing population-based, nonepisodic care supported by network organizations. These networks provide administration, budget holding, incentivized programs, data feedback, peer review, education, human relations, and health information technology support and resources. Key elements include enrolled populations; an interdisciplinary team approach; health information technology interoperability and access between all providers as well as patients; devolution of hospital-based services into the community; intersectorial integration; blended payments (a combination of universal capitated funding, patient copayments, and targeted fee-for-service for specific items); and a balance of clinical, corporate, and community governance. In this article, we discuss reforms to NZ's primary care arrangements over the past 2 decades and reflect on the lessons learned, their relevance to the United States, and issues that remain to be resolved. (J Am Board Fam Med 2012;25:S39-44.)

Keywords: Delivery of Health Care, Integrated Health Care Systems, Health Care Reform, New Zealand, Primary Health Care

Overall Health System Design in New Zealand New Zealand (NZ) has a population of 4.4 million, of whom $15 \%$ are indigenous Māori, plus a large

This article was externally peer reviewed.

Submitted 22 June 2011; revised 22 November 2011; accepted 28 November 2011.

From the Department of General Practice and Primary Health Care, University of Auckland, New Zealand (FG-S); the Centre for Health Systems, Department of Preventive and Social Medicine, University of Otago, Dunedin, New Zealand (RG); the Health Services Research Centre, School of Government, Wellington, New Zealand (JC); General Practice New Zealand (BO) and the Royal New Zealand College of General Practitioners (HP), Wellington; and West Coast District Health Board, New Zealand (PM).

Funding: Funding assistance has been received from the US Agency for Healthcare Research and Quality; the Commonwealth Fund, New Zealand Trade and Enterprise; General Practice New Zealand; and the Royal New Zealand College of General Practitioners.

Conflict of interest: none declared.

Corresponding author: Felicity Goodyear-Smith, MBChB, MGP, FRNZCGP, Department of General Practice \& Primary Health Care, Faculty of Medicine \& Health Science, University of Auckland, PB 92109, Auckland 1142, New Zealand (E-mail: f.goodyear-smith@auckland.ac.nz). immigrant Pacific population. ${ }^{1}$ The health system has a 100-year legacy crafted from social democratic roots, with societal expectations of significant state investment in universally funded and accessible health care. NZ has a central governmentdriven, tax-funded health system with the state as dominant payer. Thus, in broad conceptual terms, the NZ health system is similar to the UK health system. Commitment to the health of indigenous Māori means that reductions in inequalities are a key goal of the system. ${ }^{2}$ New Zealanders have free access to emergency, hospital, maternity, and some well-child services. Access to general practice is through enrolment with a primary care network. Population-based funding is distributed to 20 geographically-based district health boards (DHBs), which provide hospital services and contract for primary and community care services. Government-subsidized primary care is supplemented by patient copayments. Approximately 30\% of the population purchases private health insurance 
cover for elective procedures and primary care copayments, which makes up about $5 \%$ of total expenditure. ${ }^{3}$ Primary medical care largely is provided by general practitioners (GPs) in private practice. Approximately 4000 GPs and 4000 practice nurses work in 1000 practices organized through $\sim 50$ locality-based primary care networks. GPs are the point of first contact ("gatekeepers") into other primary care services (including prescribing medicines and ordering investigations) and the secondary care system.

\section{Primary Care Models}

Over the past 20 years, NZ has moved from fully independent, autonomous general practices providing individual care to a system of multidisciplinary networks that provide a range of support to general practice. These networks began in response to major health system reforms in the early 1990s, including the establishment of purchasing authorities to contract for a wide range of provider services. ${ }^{4-9}$ GPs formed primary care networks, mostly Independent Practitioner Associations (IPAs), introducing a meso level of support for general practice. ${ }^{10}$ By the end of the decade, $>80 \%$ of GPs were members of such networks, which were pivotal to "organized primary care."11 Led by doctors, they were examples of "clinical governance," promoting computerization and networking, use of clinical guidelines, various public health programs, maintenance of budgets for prescribing and laboratory testing, and engagement in comparative-effectiveness research and dissemination. ${ }^{12-14}$ These changes resulted in a shift from physician autonomy to incorporation of peer review. ${ }^{14}$

The 2001 Primary Health Care Strategy aimed for a primary care-led health system with an emphasis on health promotion, prevention, and population-based care; community governance; population-based funding; and multidisciplinary providers. ${ }^{15}$ This was implemented through new primary health organizations (PHOs) with universal primary care subsidies via capitation; nearly $100 \%$ of New Zealanders enrolled through a PHO. ${ }^{16}$

At the time, this political environment was seen to be inherently antiprivate business and anti-medical-dominance in primary care. ${ }^{17}$ Many doctors saw IPAs as their organizational preference. With infrastructure already in place, IPAs remained an important part of the primary care landscape, either establishing themselves as PHOs, linking with other groups to become PHOs, or providing management support services on contract to PHOs. ${ }^{14}$ Although there was a large injection of government funding into primary care, subsidies came with government control of fees in practices serving highneed populations, which received extra funding to improve access. However, general practice largely maintained its right to set patient fees at the point of service. Because governments traditionally have failed to adjust subsidies to keep pace with general inflation, the only ways to maintain levels of revenue have been to increase enrolled patient numbers, increase fees, or cut costs.

With capitation requiring a formal system of patient enrolment, further computerization was encouraged, with unique identifiers for patients (the National Health Index) and providers and the accumulation of rich datasets including practice population demography, which enabled an improved understanding of the needs and use of services by enrolled patients. The present government (elected in 2008) reflected the widespread view within the sector that many PHOs were too small (half had $<20,000$ enrolled patients) and ineffectual, and it ordered mergers. ${ }^{18}$ Although management services costs indicate that $>75,000$ enrolled patients is optimal for cost efficiency, ${ }^{19}$ networks have evolved. The initial focus was to develop functional relationships and a sense of ownership among clinicians. As capacity and confidence has grown, there has been a natural tendency to merge, although this may come at the cost of less local community and provider engagement. Most networks have done a good job of provider engagement, but there has been a lack of clarity around how to best engage the community; being larger could create additional challenges in this regard.

Currently, 9 groups are commissioned to deliver horizontal and vertical integration of services involving a wider range of primary care providers and devolution of secondary care services to primary care under the government's Better, Sooner, More Convenient policy. ${ }^{20}$ This will include development of integrated family health centers as one model. These reflect the current focus on expanding clinical networks, drawing on GPs, nurses, community pharmacists, and other primary care providers to deliver services through more teamwork. The primary/secondary interface could blur with more choices for patient care between home and hospital. Linkages with other sectors involved 
in the broader determinants of health (such as housing and employment agencies) should increasingly complement the work of general practice.

\section{Infrastructure}

Typically, practices have been privately owned, small, and not purpose-built. Some funding is available for GP teachers, but many practices lack the necessary space and facilities to take on trainees.

The networks supply practices with shared management services supporting patient enrolment, funding, health information technology (HIT), procurement, human relations, workforce planning and recruitment, management training, contract negotiation for additional services, continuing professional development across disciplines (GPs, nurses, and practice managers), business analysis, and crisis management. The networks have set out to promote best practices and a culture of collegiality.

Lack of capital investment in infrastructure may, however, limit the capacity of new integrated centers to house the numerous non-inpatient services currently delivered in hospitals but that gradually may be moved into community settings. Such services include clinical, chronic disease management, social, mental health, first specialist assessments, after-hour services, and day-stay procedures such as endoscopy.

A "hub and spoke" approach should enable networks to diversify the nature and location of services. Shared network-employed providers such as respiratory or diabetic educators, community health workers, or immunization coordinators may visit homes, workplaces, schools, and marae (Māori community complexes) as well as practices.

$\mathrm{NZ}$ has a good systematic approach to preventive care such as screening, recall, and cardiovascular risk assessment augmented with decision support tools and a unique identifier, the National Health Index. Geocoding allows practitioners and researchers to map health information to the individual household level and therefore learn more about neighborhood effects on health.

\section{Creating and Sustaining Change/Transformation}

The IPA movement occurred in an era before which little had changed in primary care for 40 years. Drivers were both perceived external threats and the intellectual challenge to allow clinical leaders to step forward and innovate. IPAs were seen to be successful because they were clinically led change management organizations and were trusted by GPs for this rea- son. ${ }^{21}$ Peer influence and modeling also have been seen to help practitioners embrace change through networking and collective strength. ${ }^{17}$

\section{Quality and Safety}

Registered health professionals in $\mathrm{NZ}$ are required to maintain professional standards legislated through the Health Practitioners Competence Assurance Act, regulated through their responsible authorities. ${ }^{22}$ All medical students have placements in general practices during their clinical training. General practice training programs were developed for residents as a pathway to fellowship of the Royal New Zealand College of General Practitioners. The standard full-time program is 3 years, completed in 2 stages. The first year involves supervised work in a general practice plus teaching sessions and then sitting the Primex examination. There are a further 2 years of clinical practice before the fellowship assessment to obtain vocational registration. The College also developed the Aiming for Excellence Cornerstone practice accreditation (with a defined set of standards), supported by central government. ${ }^{23}$ Practice accreditation is voluntary, with $80 \%$ of practices participating. Some networks make practice accreditation a requirement of joining a network.

A number of government initiatives aim to improve quality of care, including a Health and Disability Commissioner and a National Health Board charged with improving the quality, safety, and sustainability of health care. This board has subcommittees, including the National IT Board to provide leadership for the implementation and use of information systems and Health Workforce NZ to coordinate the planning and development of the country's health workforce. A Health Quality and Safety Commission works with providers to improve quality and safety of services. The $20 \mathrm{DHBs}$ report sentinel and serious events.

At a local level, early network initiatives resulted in achievement of practitioner-determined targets for activities such as recording ethnicity and smoking status and keeping registers and recall systems for cervical smear, mammography, immunization, and well-child checks. This is in line with international evidence that supported professionalism in the form of peer review and benchmarking as an effective tool to reduce provider variability. ${ }^{24}$ Networks have worked to support implementation of guidelines and provide decision support tools and opportunity for local and regional experiments. 
They have also driven quality, coordination, efficiency, and accountability. Patients First, a joint program of the Royal New Zealand College of General Practitioners and the overarching network organization General Practice New Zealand, funded by the National HIT Board, is pursuing projects that integrate quality and information for primary care. ${ }^{25}$ Still lacking are systematic ways to feed information back into the health system and mechanisms to seek, understand, and incorporate the patient's experience to enable patient participation-issues that the more integrated primary care models are now trying to address.

PHC academics have major barriers to accessing practices for audit data and research. Patient $\mathrm{PHO}$ enrollment should include consent to use unidentifiable data constructively and, unless a practice actively chooses to opt out, all collated anonymous practice data should be made available for analysis. This would increase knowledge of quality of care and enable identification of key characteristics of high-performing models.

\section{Payment/Incentives}

NZ now has a payment system that combines a universal capitated general medical subsidy, patient copayments, and targeted fee-for-service payments for specific items such as comprehensive free reviews for patients with diabetes, care of other chronic conditions, and immunizations.

In NZ, the benefits of capitation have been found to include better use of provider mix (services for which GPs previously had to provide to claim benefits can now be delivered by other team members, usually practice nurses); patient enrolment (the relationship between patient and provider is more explicit, allowing greater accountability for provider behavior); and accurate demographic information. This also provides a rich data platform for individual and population care, quality improvement activities, planning, and research.

Regional networks manage their funding through a contract mechanism and may fund specific clinical programs with their own reporting and accountability requirements, reflecting that there are sometimes considerable differences by region in terms of service focus and organization. Incentivized programs include avoidable admissions, mental health referrals, and maternity care. There also are network performance measures such as breast and cervical screening with targeted funding and comparative bench-marking between networks.

The PHO Performance Program (national payfor-performance scheme $)^{26}$ has shown significant improvement in some, but not all, activities. Some established networks were already achieving the targets but gained indirect benefit through using performance payments to fund local education and quality activities. Others, particularly smaller or newer networks, found considerable benefit from the program. ${ }^{27,28}$

\section{Referred Services and Clinical Performance Indicators}

Accountability is required of GPs, practices, management services organizations, PHOs, and DHBs. The current model of care allows for systematic measurements and benchmarking, but measures tend to be those requested by government, easy to measure, or where there are available data. These are measures of process rather than actual health outcomes. Focus often has been on diseases rather than the overall health of patients.

Moving to capitated funding has not, however, changed the transactional nature of GP 15-minute consulting because patient fee-for-service payments remain a significant portion of income. To shift away from this approach and achieve the current government's slogan of "better, sooner, more convenient" health care ${ }^{18}$ requires a different funding model that has less emphasis on patient fees, which remain a barrier to seeking care for approximately $20 \%$ of New Zealanders. ${ }^{29,30}$

How health care is funded is important as well as how much is funded. Without professionalism, all payment types (salary, capitation, fee for service, and target-driven) can be exploited. There is a current trend in NZ away from owner-operated practices to salaried GPs. Yet practitioner ownership may turn out to be an important driver of delivery of high-quality care, for both emotional (people are committed to change directed from the bottom up) and financial (GPs who own their practices invest in the hours required to provide quality care) reasons. If corporate ownership of groups of practices progresses, incentives to perform may change.

The frequent changes to the NZ health system affect processes, ${ }^{31}$ but primary care outcomes are unknown. A move from indicators to value-based outcome measures is needed alongside increased 
Table 1. Lessons Learned from the New Zealand (NZ) Experience for US Health Reform

Value of networks

Population approach

Clinical, community, and corporate governance

Blended payments

Interdisciplinary team approach

HIT interoperability

Intersectorial integration

Health outcomes
Network organizations have provided administration, budget holding, incentivized programs, data feedback, peer review, education, human relations, and HIT support and resources. Such organizations have been found to play a key role in better supporting primary care services and service development.

NZ has successfully enrolled patients with a unique patient identifier (National Health Index) supporting this enrolment. This has allowed networks and providers to focus increasingly on achieving improved health for their enrolled population and has improved accountability through the ability to identify the population being cared for and assess progress in achieving key targets.

NZ has developed a mix of clinical, community, and corporate governance arrangements, although how well this mix works is not well researched.

NZ has successfully introduced a mix of salary, capitation, fee-for-service, and target-driven payments, although the impact of these changes is not well researched.

There is increasing teamwork between doctors, nurses, community pharmacists, other allied health workers.

Improved interoperability is gradually allowing providers to access records and will over time be available to patients as well.

The government currently is seeking increased devolution of hospitalbased services into the community to ensure "better, sooner, and more convenient" services and to reduce pressure on hospitals. The extent of devolution and its impact is not well researched.

With several years of investment in organized primary care, data show some improvements in patient outcomes. These include rates of immunization; routine screening of patients at risk for cancers, cardiovascular disease, and diabetes; and care coordination of chronic disease patients, with corresponding reductions in hospitalizations.

HIT, health information technology.

trust in professionalism, rather than focusing on select process indicators. Primary care is more complex than procedural medicine, which has discrete episodes of care and more proscribed outcomes to measure. Evaluation of global budget holding (for laboratory services, pharmaceuticals, immunization, acute demand, and general medical services) found greater flexibility, enabling the development of innovative practice, an emphasis on teamwork, and increased involvement by practice nurses. ${ }^{32}$ There is a demand in NZ that consideration be given to rewarding vocational training and practice accreditation.

\section{Conclusion}

The NZ experience precedes and endorses the concept of patient-centered medical homes ${ }^{33}$ providing population-based, nonepisodic care supported by network organizations. These networks provide administration, budget holding, incentivized programs, data feedback, peer review, education, human relations, HIT support, and resources. Key elements include enrolled populations, an interdisciplinary team ap- proach, HIT interoperability and access between all providers as well as patients, devolution of hospitalbased services into the community, intersectorial integration, blended payments, and a balance of clinical, corporate, and community governance. Several lessons for the United States may be gleaned from the $\mathrm{NZ}$ experience. On the downside, regular government-imposed restructuring of the broader health system and of primary care has been a distraction over the years. On the upside, however, as summarized in Table 1, the NZ experience suggests that there is considerable value in organized primary care and that clinicians can play an important leadership role in this. With organization and shared infrastructure, such as HIT, there also is increased potential for focusing on populations and disease management rather than the episodic care that is driven by the predominant fee-for-service model in the United States.

\section{References}

1. Statistics New Zealand. 2006 Census data. Available at http://www.stats.govt.nz/Census/2006CensusHome Page.aspx. Accessed January 25, 2012. 
2. New Zealand Treaty of Waitangi Act of 1975, Public Act 114, Schedule 1 (1975).

3. Ministry of Health. Health expenditure trends in New Zealand, 1990-2006. Wellington: Ministry of Health; 2008.

4. Ashton T. The purchaser-provider split in New Zealand: the story so far. Aust Health Rev 1995;18:43-60.

5. Ashton T. The health reforms: to market and back? In: Boston J, Dalziel P, St John S, eds. Redesigning the Welfare State in New Zealand: Problems, Policies, Prospects. Auckland: Oxford University Press; 1999:134-53.

6. Ashton T, Cumming J, McLean J. Contracting for health services in a public health system: the New Zealand experience. Health Policy 2004;69:21-31.

7. Ashton T, Cumming J, McLean J, McKinlay M, Fae E. Contracting for health services: lessons from New Zealand. Manila, Philippines: Regional Office for the Western Pacific, World Health Organization; 2004.

8. Cumming J, Salmond G. Reforming New Zealand health care. In: Ranade W, ed. Markets and Health Care: A Comparative Analysis. New York: Addison Wesley Longman; 1998.

9. Gauld R. Revolving doors: New Zealand's health reforms - the saga continues. Wellington: Institute of Policy Studies and Health Services Research Centre; 2009.

10. Barnett P. Into the unknown: the anticipation and experience of membership of independent practitioner associations. N Z Med J 2003;116:U382.

11. Malcolm L, Wright L, Barnett P. The development of primary care organisations in New Zealand: a review undertaken for Treasury and the Ministry of Health. Wellington: Ministry of Health; 1999.

12. Malcolm L, Wright L, Barnett P. Emerging clinical governance: developments in independent practitioner associations in New Zealand. N Z Med J 2000;113:33-6.

13. Malcolm L, Mays N. New Zealand's independent practitioner associations: a working model of clinical governance in primary care? BMJ1999;319:1340-2.

14. Gauld R, Mays N. Are New Zealand's new primary health organisations fit for purpose? BMJ 2006;333: 1216-8.

15. King A. The primary health care strategy. Wellington: Ministry of Health; 2001.

16. Annette King; Ministry of Health. Implementing the New Zealand Health Strategy 2002: The Minister of Health's Second Report on Progress on the New Zealand Health Strategy. Available at: http://www.health.govt.nz/about-ministry/corporate-publications/implementing-new-zealand-health-strategy Accessed January 25, 2012.

17. Gauld R. The unintended consequences of New Zealand's primary care reforms. J Health Polit Policy Law 2008;33:93-117.

18. Ryall H. Better, sooner, more convenient. Health discussion paper. Wellington: National Party of New Zealand; 2007. Available at http://www.nationalhealthboard. govt.nz/sites/all/files/BSMC\%20ebooklet.pdf.
19. Jordan C, McCardle J, Norgrove K. Review of primary health organisation management services: report to the Ministry of Health. Auckland: Capital Strategy Limited; 2004:127.

20. Ministry of Health. Request for expression of interest (eoi) for the delivery of better, sooner, more convenient primary health care. Wellington: Ministry of Health; 2009:15.

21. Gauld R, Mays N. Reforming primary care: are New Zealand's new primary health organisations fit for purpose? Br Med J 2006;333:1216-8.

22. New Zealand Government. Health Practitioners Competence Assurance Act of 2003, Public Act 48, Part 3: Competence, fitness to practise, and quality assurance (2003).

23. Royal New Zealand College of General Practitioners. Aiming for excellence. Wellington: Royal New Zealand College of General Practitioners; 2000:99.

24. Greene RA, Beckman HB, Mahoney T. Beyond the efficiency index: finding a better way to reduce overuse and increase efficiency in physician care. Health Aff 2008;27:w250-9.

25. Patients First. Quality and information for primary care in New Zealand. Wellington: Patients First; 2011.

26. HealthPAC. Performance monitoring framework: data format standard clinical performance indicators. Wellington: Ministry of Health; 2006:42.

27. Pinnacle. Response to the draft operational framework for primary health organization performance management. Hamilton, New Zealand: Pinnacle Primary Health Organisation. 2005:7.

28. Ministry of Health. Feedback from the sector on the performance framework, RSM and CPI components. Wellington: Ministry of Health; 2005:12.

29. Conrad DA. Incentives for health-care performance improvement. In: Smith PC, Mossialos E, Papanicolas I, Leatherman S, eds. Performance Measurement for Health System Improvement: Experiences, Challenges and Prospects. Cambridge: Cambridge University Press; 2009:582-612.

30. Jatrana S, Crampton P. Primary health care in New Zealand: who has access? Health Policy 2009;93:1-10.

31. Davis P, Lay-Yee R, Scott A, Gauld R. Do hospital bed reduction and multiple system reform affect patient mortality? A trend and multilevel analysis in New Zealand over the period 1988-2001. Med Care 2007;45:1186-94.

32. Kirk R, Barnett P, Clayden C, et al. Evaluation of the Pegasus Health global budget contract. 2002:359. Available at http://nzhta.chmeds.ac.nz/publications/ phevaluation_report.pdf. Accessed January 25, 2012.

33. American Academy of Family Physicians, American Academy of Pediatrics, American College of Physicians, American Osteopathic Association. Joint Principles of the Patient-Centered Medical Home, 2007:3. Available at: http://www.pcpcc.net/content/joint-principles-patientcentered-medical-home. Feb 2007. Accessed February 2, 2012. 